\title{
Intake of fruits and vegetables in smokers
}

\author{
Nicholas J Birkett \\ Department of Epidemiology and Community Medicine, University of Ottawa, Ottawa, Ontario, Canada
}

Received 1 May 1998: Accepted 21 May 1998

\begin{abstract}
Objectives: To examine intake of fruits and vegetables in smokers and non-smokers. Design: Secondary analysis using general linear modelling approaches. Food intake measured using a food frequency questionnaire approach.

Setting: The community (the population of the province of Ontario, Canada).

Subjects: Members of the general public $(n=38,000)$.

Results: Smokers ate substantially less fruit and fruit juice then non-smokers with heavy smokers eating the least. Heavy smokers were between four and six times more likely to be eating less fruit than recommended. Similar but less marked differences were noted for vegetable intake. Smokers also obtained a larger part of their total caloric intake from fats.

Conclusions: While smoking cessation remains the primary target for lung cancer prevention, attention should also be given to dietary interventions in smokers in order to improve their nutrition. Such interventions might also be expected to reduce the risk of other cancers (e.g. colon cancer).
\end{abstract}

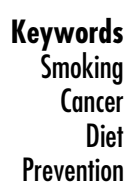

Tobacco smoking has been established as the leading cause of lung cancer ${ }^{1}$. Dietary intake, particularly the low intake of fruits and vegetables, has also been established as a risk factor for various cancers, including lung cancer ${ }^{2}$. In 1992, Block et al. ${ }^{2}$ published a comprehensive review of the evidence linking diet to lung cancer risk. Of 25 studies which examined nutrient intake, 24 found a significantly lower risk of lung cancer in people who ate 'high' amounts of vegetables and fruits (RR around 0.5 ). This protective effect persisted after adjustment for smoking and on stratified analysis within subgroups of smokers. Hence, knowledge of the dietary habits of smokers can contribute to an understanding of their risk of lung cancer.

Several studies have examined the intake of foods ${ }^{3-8}$ and nutrients ${ }^{3-5,7,9}$ in smokers compared to nonsmokers in people living in the USA, The Netherlands and England. In general, the data suggest that smokers, and in particular heavy smokers (20 or more cigarettes per day), have a somewhat lower intake of vegetables and a markedly lower intake of fruits. In some studies, this translates into lower intake of nutrients such as vitamins $\mathrm{A}, \mathrm{C}$ and $\mathrm{E}$, and $\beta$-carotene.

The present study employs data from the Ontario Health Survey (OHS) to replicate these observations on the relationship between smoking and food/nutrient intake in a random sample of Canadian residents. These results support the published literature in suggesting that the diets of smokers place them at higher risk of developing lung cancer than from their smoking habit alone.

\section{Methods}

\section{The Ontario Health Survey}

The OHS was conducted by the Ontario Ministry of Health in 1990. The detailed survey methods are available from other sources ${ }^{10}$ and only a summary of the relevant aspects will be presented here. The OHS employed complex multistage area sampling methods to obtain a sample of 35,479 Ontario dwellings. The province was stratified into 42 primary strata with each stratum being substratified into rural and urban strata. The primary sampling units were the enumeration areas from the 1986 Canadian census. Within each stratum, an average of 46 enumeration areas was selected using probability proportional to estimated population size. Within each selected enumeration area, a complete list of dwellings was produced and a random selection of 15 urban, or 20 rural, dwellings was chosen. All people living in the selected dwellings were eligible for study. A self-administered questionnaire was completed by each person in the household over the age of 12 . This questionnaire addressed a variety of personal health matters including smoking and nutrition. Response to this questionnaire was 
Table 1 Characteristics of the study population

\begin{tabular}{|c|c|c|c|c|c|c|}
\hline & \multicolumn{5}{|c|}{ Smoking status } & \multirow[b]{2}{*}{$P$ value } \\
\hline & Never & Former & $\begin{array}{c}\text { Light } \\
\left(1-9 \text { day }^{-1}\right)\end{array}$ & $\begin{array}{c}\text { Moderate } \\
\left(10-19 \text { day }^{-1}\right)\end{array}$ & $\begin{array}{c}\text { Heavy } \\
\left(\geq 20 \text { c day }^{-1}\right)\end{array}$ & \\
\hline \multicolumn{7}{|l|}{ Men } \\
\hline Number of people (\%) & $6246(37.5)$ & $5398(32.4)$ & $720(4.3)$ & $3409(20.5)$ & $877(5.3)$ & \\
\hline Age in years & 39.1 & 51.0 & 39.0 & 38.4 & 43.5 & $<0.0001$ \\
\hline Body mass index & 25.1 & 26.0 & 24.6 & 25.0 & 25.9 & $<0.0001$ \\
\hline \multicolumn{7}{|l|}{ Educational level } \\
\hline$\%$ primary & 7.5 & 12.8 & 11.8 & 10.1 & 12.7 & \\
\hline$\%$ some secondary & 14.5 & 22.6 & 24.8 & 30.7 & 34.4 & \\
\hline$\%$ secondary & 22.5 & 24.1 & 24.4 & 28.2 & 24.5 & \\
\hline$\%$ some post-2nd & 16.6 & 11.8 & 16.5 & 12.8 & 11.8 & \\
\hline$\%$ post-2nd & 39.0 & 28.7 & 22.5 & 18.2 & 16.6 & $<0.0001$ \\
\hline Energy intake $\left(\mathrm{kcal} \mathrm{day}^{-1}\right)$ & 2411 & 2312 & 2547 & 2650 & 2681 & $<0.0001$ \\
\hline \multicolumn{7}{|l|}{ Women } \\
\hline Number of people (\%) & $9852(51.3)$ & $4203(21.9)$ & $1101(5.7)$ & $3613(18.8)$ & $455(2.4)$ & \\
\hline Age in years & 44.6 & 45.8 & 39.2 & 39.8 & 41.7 & $<0.0001$ \\
\hline Body mass index & 23.8 & 24.3 & 22.7 & 23.5 & 24.2 & $<0.0001$ \\
\hline \multicolumn{7}{|l|}{ Educational level } \\
\hline$\%$ primary & 12.3 & 6.2 & 4.8 & 7.1 & 7.5 & \\
\hline$\%$ some secondary & 17.5 & 19.7 & 24.9 & 29.6 & 36.3 & \\
\hline$\%$ secondary & 25.5 & 29.9 & 30.0 & 32.2 & 30.3 & \\
\hline$\%$ some post-2nd & 14.5 & 13.8 & 15.0 & 13.2 & 10.9 & \\
\hline$\%$ post-2nd & 30.2 & 30.4 & 25.4 & 17.9 & 15.0 & $<0.0001$ \\
\hline Energy intake $\left(\mathrm{kcal}^{\mathrm{day}}{ }^{-1}\right)$ & 1987 & 1986 & 2015 & 2111 & 2290 & $<0.0001$ \\
\hline
\end{tabular}

c, cigarettes.

$77.2 \%$. For this analysis, children under age 18 were excluded, yielding completed questionnaires from 43,954 people (20,431 male and 23,523 female).

\section{Measurement of variables}

The self-administered questionnaire included an 82item food frequency questionnaire (FFQ) which was used to estimate usual food intake ${ }^{11}$. This questionnaire was developed for the OHS and was modelled after that of Block et al. $^{12}$. Validation information has been published by Bright-See et al. ${ }^{13}$. For each food item, information was obtained concerning the usual frequency of consumption and the usual serving size. Using data from the Canadian Nutrient Data File, the food frequency information was converted into estimated intake for a range of nutrients using processes developed for the OHS research offices ${ }^{14}$. Estimated intake for each food item was converted into serving-size units. For reporting in this article, attention was focused on food items which were either vegetables, fruits or juices. These were further classified into several larger groupings for reporting (Appendix 1). Nutrient estimates are based on the entire FFQ, not just the fruit and vegetable items.

All subjects were asked about their current smoking habits and the amount smoked per day. Subjects were classified into five groups: Never Smoked, Former Smoker, Light Smoker (1-9 cigarettes per day), Moderate Smoker (10-19 cigarettes per day) and Heavy Smoker (20 or more cigarettes per day). No biochemical validation of reported smoking was performed. Subjects also reported their age (in years), educational level (five levels), weight, height and sex. Self-reported weight and height were used to estimate body mass index (BMI) as weight/height ${ }^{2}\left(\mathrm{~kg} / \mathrm{m}^{2}\right)$.

Subjects who reported eating excessive amounts of any of the food items (amounts which were more than five standard deviations above the mean intake) were excluded from all analyses leaving a final sample size of 40,085 (91.2\%). The sample size for the analyses was further reduced through missing data on the measured variables using a listwise deletion approach.

In addition to reporting estimated intake, subjects were compared for adherence to suggested cut-points for increased cancer risk. Block et $a l^{2}$, in their discussion of diet and lung cancer, present several cut-points which have been used in the literature to identify groups at increased risk of developing cancer. For comparison purposes, the fruit and vegetable intake was classified according to four of these criteria (under three servings of fruit or fruit juice per week; under three servings of fruit per week; under 11 servings of fruit and vegetables per week; under $200 \mathrm{~g}$ of vegetables per day).

\section{Statistical analysis}

General linear modelling approaches were adopted to examine differences in food and nutrient intake in the five smoking groups. Sex-specific analyses are reported and all analyses are adjusted for age, education, BMI and daily energy intake. All analyses are weighted to reflect the differential probability of subject selection to the sample. Weights were provided by the OHS research office and include a postsampling adjustment 
Table 2 Mean number of servings per week by smoking status adjusted for age, body mass index, level of education and daily energy intake

\begin{tabular}{|c|c|c|c|c|c|c|c|}
\hline & \multicolumn{5}{|c|}{ Smoking status } & \multirow[b]{2}{*}{ Wald F† } & \multirow[b]{2}{*}{$P$ value } \\
\hline & Never & Former & $\begin{array}{l}\text { Light } \\
\left(1-9 \text { day }^{-1}\right)\end{array}$ & $\begin{array}{c}\text { Moderate } \\
\left(10-19 \mathrm{c} \mathrm{day}^{-1}\right)\end{array}$ & $\begin{array}{c}\text { Heavy } \\
\left(\geq 20 \mathrm{c} \mathrm{day}^{-1}\right)\end{array}$ & & \\
\hline \multicolumn{8}{|l|}{ Men } \\
\hline Total vegetables & $16.8^{\star}$ & 17.0 & 17.3 & 16.0 & 16.4 & 3.1 & 0.014 \\
\hline Cruciferous veg. & 1.7 & 1.7 & 1.9 & 1.4 & 1.4 & 9.7 & $<0.0001$ \\
\hline Potatoes (all) & 5.2 & 5.7 & 5.3 & 6.0 & 6.1 & 12.2 & $<0.0001$ \\
\hline Potatoes (no chips) & 4.1 & 4.4 & 4.2 & 4.7 & 4.8 & 10.5 & $<0.0001$ \\
\hline Fruit (all) & 10.6 & 10.0 & 9.6 & 7.0 & 6.4 & 59.5 & $<0.0001$ \\
\hline Fruit (non-citrus) & 8.3 & 7.8 & 7.3 & 5.4 & 5.1 & 64.6 & $<0.0001$ \\
\hline Fruit (citrus) & 12.2 & 11.2 & 10.2 & 8.8 & 7.2 & 27.5 & $<0.0001$ \\
\hline Juice (fruit \& veg.) & 11.0 & 10.3 & 9.0 & 8.7 & 7.6 & 13.0 & $<0.0001$ \\
\hline \multicolumn{8}{|l|}{ Women } \\
\hline Total vegetables & 16.4 & 17.6 & 16.0 & 15.7 & 14.9 & 12.1 & $<0.0001$ \\
\hline Cruciferous veg. & 2.0 & 2.2 & 1.9 & 1.6 & 1.8 & 12.7 & $<0.0001$ \\
\hline Potatoes (all) & 4.1 & 4.4 & 4.4 & 4.9 & 4.8 & 14.3 & $<0.0001$ \\
\hline Potatoes (no chips) & 3.3 & 3.5 & 3.5 & 3.8 & 3.7 & 6.6 & $<0.0001$ \\
\hline Fruit (all) & 11.0 & 10.2 & 8.4 & 7.1 & 5.3 & 80.5 & $<0.0001$ \\
\hline Fruit (non-citrus) & 8.5 & 8.1 & 6.5 & 5.6 & 4.2 & 72.5 & $<0.0001$ \\
\hline Fruit (citrus) & 11.6 & 9.9 & 9.5 & 8.1 & 8.3 & 29.8 & $<0.0001$ \\
\hline Juice (fruit \& veg.) & 10.1 & 8.9 & 8.8 & 7.6 & 8.7 & 15.8 & $<0.0001$ \\
\hline
\end{tabular}

c, cigarettes.

*Mean intake (adjusted for BMI, age, education and daily caloric intake) from SAS Proc GLM (LSMEANS) using weighted data.

† Numerator degrees of freedom are 4 for all tests. Denominator degrees of freedom are over 15,000 for all tests. This test (and the $P$ value) test the overall hypothesis that the mean food intake in the five smoking groups is the same.

for non-response. Due to the complex sampling strategy employed in this survey, specialized software (SUDAAN, Research Triangle Institute, Research Triangle Park, North Carolina) was used to perform hypothesis testing and to generate confidence intervals. Post-hoc comparisons between smoking groups used contrasts. The adjusted mean intake of the nutrients within each smoking group was obtained using the LSMEANS option of proc GLM in SAS (SAS Institute Inc., Cary, North Carolina) employing a weighted regression model. In light of the multiple testing undertaken, caution should be used in interpreting $P$ values over 0.01 .

\section{Results}

Table 1 shows the characteristics of the sample by smoking status, stratified by sex. The mean age of the various smoking groups was more similar in women than in men where male Former Smokers were about 12 years older than male Never Smokers. The proportion of Never Smokers was higher in women than in men. Contrary to other studies, self-reported BMI increased with the number of cigarettes smoked per day and was similar in Former Smokers and Heavy Smokers. Daily energy intake also increased with amount smoked and was higher in Heavy Smokers than in Never Smokers. These observations persisted after adjustment for age (results not shown here).

An overall test for differences in vegetable intake for the various categories of smoking was statistically significant (Table 2) although the magnitudes of the differences were small. Post-hoc contrasts for men grouped Moderate and Heavy Smokers together and the other three groups together. For total vegetables and cruciferous vegetables, smokers ate fewer servings per week while intake of potatoes (with and without including potato chips) by smokers was slightly higher. For women, no clear grouping of smoking categories emerged from the post-hoc testing although, in general, smokers tended to have lower intake of vegetables.

Much larger differences were noted for fruit and juice intake. Heavy Smokers reported eating fewer servings of fruit and juice than did Never Smokers (between 50 and $80 \%$ of the number eaten by Never Smokers). For fruit intake in women, there was evidence that the five smoking groups had different intakes with a doseresponse gradient with amount smoked. A similar pattern was present for men, achieving statistical significance for citrus juice intake.

Data on intake of selected nutrients is presented in Table 3 (based on the entire FFQ). For men, all comparisons were statistically significant although for two nutrients (vitamin A and niacin), the significance was marginal given the multiple comparisons performed. For women, most comparisons were strongly significant, except for riboflavin, vitamin A and calcium. Compared to Never Smokers, Heavy Smokers have 'meaningfully' lower intake of calcium (in men only), vitamin $\mathrm{C}$ and fibre. They have a higher intake of cholesterol and obtain a larger proportion of their total caloric intake from fat. Little difference was noted for the intake of niacin, riboflavin, thiamin and vitamin A. Post-hoc comparisons revealed strong differences between Heavy and Moderate Smokers 
Table 3 Mean daily nutrient intake by smoking status adjusted for age, body mass index, level of education and daily energy intake

\begin{tabular}{|c|c|c|c|c|c|c|c|}
\hline & \multicolumn{5}{|c|}{ Smoking status } & \multirow[b]{2}{*}{ Wald F† } & \multirow[b]{2}{*}{$P$ value } \\
\hline & Never & Former & $\begin{array}{c}\text { Light } \\
\left(1-9 \text { day }^{-1}\right)\end{array}$ & $\begin{array}{c}\text { Moderate } \\
\left(10-19 \mathrm{c} \text { day }^{-1}\right)\end{array}$ & $\begin{array}{c}\text { Heavy } \\
\left(\geq 20 \text { c day }^{-1}\right)\end{array}$ & & \\
\hline \multicolumn{8}{|l|}{ Men } \\
\hline Calcium (g) & $1144^{*}$ & 1133 & 1175 & 1099 & 1048 & 6.7 & $<0.0001$ \\
\hline Iron $(\mathrm{g})$ & 15.1 & 15.0 & 15.0 & 14.4 & 14.2 & 11.4 & $<0.0001$ \\
\hline Vitamin A (RE) & 1715 & 1730 & 1823 & 1652 & 1752 & 2.8 & 0.024 \\
\hline Vitamin C (mg) & 153.8 & 145.1 & 144.5 & 125.0 & 111.0 & 26.1 & $<0.0001$ \\
\hline Thiamin (mg) & 1.7 & 1.7 & 1.7 & 1.6 & 1.5 & 18.6 & $<0.0001$ \\
\hline Riboflavin (mg) & 2.5 & 2.5 & 2.5 & 2.3 & 2.3 & 10.9 & $<0.0001$ \\
\hline Niacin (NE) & 40.9 & 41.4 & 42.2 & 41.4 & 41.3 & 2.4 & 0.047 \\
\hline Fat $(\%$ calories) & 37.1 & 38.5 & 38.3 & 40.4 & 41.0 & 71.6 & $<0.0001$ \\
\hline Cholesterol (mg) & 390.1 & 401.3 & 407.0 & 442.1 & 474.0 & 22.7 & $<0.0001$ \\
\hline Fibre $(\mathrm{g})$ & 21.4 & 21.1 & 20.4 & 17.8 & 16.9 & 56.4 & $<0.0001$ \\
\hline \multicolumn{8}{|l|}{ Women } \\
\hline Calcium (g) & 1027 & 1059 & 1049 & 1043 & 1012 & 2.8 & 0.026 \\
\hline Iron $(\mathrm{g})$ & 12.7 & 12.8 & 12.5 & 11.9 & 12.0 & 21.2 & $<0.0001$ \\
\hline Vitamin A (RE) & 1619 & 1647 & 1664 & 1581 & 1466 & 2.4 & 0.048 \\
\hline Vitamin C (mg) & 144.7 & 132.8 & 133.8 & 115.5 & 117.2 & 27.9 & $<0.0001$ \\
\hline Thiamin (mg) & 1.4 & 1.4 & 1.4 & 1.3 & 1.3 & 23.6 & $<0.0001$ \\
\hline Riboflavin (mg) & 2.1 & 2.1 & 2.1 & 2.1 & 2.0 & 1.9 & 0.11 \\
\hline Niacin (NE) & 33.7 & 34.6 & 34.0 & 33.5 & 34.0 & 6.0 & 0.0001 \\
\hline Fat $(\%$ calories $)$ & 35.3 & 36.4 & 37.4 & 38.5 & 39.3 & 73.8 & $<0.0001$ \\
\hline Cholesterol (mg) & 305.0 & 308.3 & 317.4 & 330.9 & 337.6 & 8.5 & $<0.0001$ \\
\hline Fibre (g) & 19.5 & 19.5 & 17.9 & 15.8 & 14.8 & 63.8 & $<0.0001$ \\
\hline
\end{tabular}

c, cigarettes.

* Mean intake (adjusted for BMI, age, education and daily caloric intake) from SAS Proc GLM (LSMEANS) using weighted data.

†Numerator degrees of freedom are 4 for all tests. Denominator degrees of freedom are over 15,000 for all tests.

for most nutrients in men while the levels in Never Smokers, Former Smokers and Light Smokers tended to be similar. However, in women, the Heavy and Moderate Smokers groups were similar but there was strong evidence of a difference between them and the other groups.

The odds ratios of eating below minimal levels of fruit and vegetables (according to the four selected cutpoints) compared to the Never Smoked category are shown in Table 4. For the first three criteria, there is a strong and statistically significant increase in likelihood of eating poorly as the amount smoked increases. The differences are most pronounced for the standards based on fruit intake alone. For the standard involving

Table 4 Odds ratio of failing to meet the specified intake levels by smoking status adjusted for age, body mass index, level of education and daily energy intake

\begin{tabular}{|c|c|c|c|c|c|c|c|}
\hline & \multicolumn{5}{|c|}{ Smoking status } & \multirow[b]{2}{*}{ Wald F\# } & \multirow[b]{2}{*}{$P$ value } \\
\hline & Never* & Formert & $\begin{array}{l}\text { Light } \\
\left(1-9 \text { day }^{-1}\right)\end{array}$ & $\begin{array}{c}\text { Moderate } \\
\left(10-19 \mathrm{c} \text { day }^{-1}\right)\end{array}$ & $\begin{array}{c}\text { Heavy } \\
\left(\geq 20 \mathrm{c} \mathrm{day}^{-1}\right)\end{array}$ & & \\
\hline \multicolumn{8}{|l|}{ Men } \\
\hline $\begin{array}{l}\text { Under } 3 \text { servings } \\
\quad \text { fruit/fruit juice week }{ }^{-1}\end{array}$ & $6.2 \%$ & $1.6(1.3,2.0)$ & $1.7(1.1,2.4)$ & $3.4(2.7,4.3)$ & $4.2(3.0,6.0)$ & 37.3 & $<0.0001$ \\
\hline $\begin{array}{l}\text { Under } 3 \text { servings } \\
\text { fruit } \text { week }^{-1}\end{array}$ & $18.5 \%$ & $1.3(1.1,1.6)$ & $1.5(1.1,2.0)$ & $2.8(2.4,3.6)$ & $4.5(3.4,5.9)$ & 53.6 & $<0.0001$ \\
\hline $\begin{array}{l}\text { Under } 11 \text { servings } \\
\text { fruits/vegetables } \text { week }^{-1}\end{array}$ & $11.8 \%$ & $1.1(0.8,1.3)$ & $1.2(0.8,1.7)$ & $1.9(1.5,2.4)$ & $2.3(1.6,3.4)$ & 10.2 & $<0.0001$ \\
\hline $\begin{array}{l}\text { Under } 200 \mathrm{~g} \\
\text { vegetables day }^{-1}\end{array}$ & $53.2 \%$ & $1.0(0.8,1.1)$ & $1.0(0.7,1.2)$ & $1.0(0.9,1.2)$ & $1.0(0.8,1.3)$ & 0.3 & 0.87 \\
\hline Women & & & & & & & \\
\hline $\begin{array}{l}\text { Under } 3 \text { servings } \\
\text { fruit/fruit juice week }\end{array}$ & $5.9 \%$ & $1.4(1.1,1.8)$ & $2.8(2.1,3.8)$ & $3.2(2.6,3.9)$ & $6.3(4.2,9.5)$ & 43.6 & $<0.0001$ \\
\hline $\begin{array}{l}\text { Under } 3 \text { servings } \\
\text { fruit week }{ }^{-1}\end{array}$ & $14.5 \%$ & $1.3(1.1,1.5)$ & $2.4(1.8,3.1)$ & $3.1(2.6,3.6)$ & $8.1(5.7,11.6)$ & 69.0 & $<0.0001$ \\
\hline $\begin{array}{l}\text { fruits } / \text { vegetables } \text { week }^{-1} \\
\text { Under } 200 \mathrm{~g}\end{array}$ & $10.5 \%$ & $0.9(0.7,1.1)$ & $1.5(1.1,2.0)$ & $2.0(1.6,2.4)$ & $3.3(2.0,5.5)$ & 20.4 & $<0.0001$ \\
\hline vegetables day $^{-1}$ & $52.3 \%$ & $0.7(0.6,0.8)$ & $1.1(0.9,1.4)$ & $1.1(0.9,1.2)$ & $1.3(0.9,1.8)$ & 7.9 & $<0.0001$ \\
\hline
\end{tabular}

c, cigarettes.

*Each entry in this column is the observed frequency with which the criterion is met for 'Never Smokers'.

$\dagger$ Each entry is the odds ratio ('Never Smoked' as reference category) followed by the 95\% confidence interval. Estimates adjusted for age, BMI, daily caloric intake and education.

\# Numerator degrees of freedom are 4 for all tests. Denominator degrees of freedom are over 15,000 for all tests. 
both fruits and vegetables, the differences among smokers are smaller with no apparent differences in the proportion of Heavy Smokers compared to Moderate Smokers who met the criteria. There are very limited differences for the standard based solely on vegetable intake although, for women, Former Smokers are more likely to meet the standard.

\section{Discussion}

Results from the OHS show that smokers eat less healthy diets than non-smokers. This is particularly noticeable for fruit intake in which Heavy Smokers eat between 20 and 50\% fewer servings of fruit per week and are between four and eight times more likely to eat under three servings of fruit per week. Intake of cruciferous vegetables is lower in smokers. Smokers also eat a diet which provides more calories from fat and has higher amounts of cholesterol and smaller amounts of fibre and calcium than do non-smokers. There is some evidence for a dose-response effect with Former Smokers being similar to Never Smokers with increasingly poor diet as the amount currently smoked increases.

In contrast to other studies, the OHS data provide no evidence that smokers have lower intakes of vitamin A. Since the OHS did not obtain information about use of vitamin supplements, this cannot be due to increased intake of vitamin supplements by smokers. The basis for this discrepancy is not clear. However, since reduced vitamin A and retinoid intake is consistently linked to increased cancer risks ${ }^{15}$, the intake of vitamin A in smokers has important public health implications.

The FFQ employed in the OHS omitted several items which would have been useful for a more definitive estimation of vegetable and fruit intake (e.g. grapefruit, mushrooms, celery). In other cases, items were grouped into one category when separate information would have been more useful (e.g. 'apple and other citrus juice', 'any other vegetables including Brussel sprouts and cabbage'). Further, some sources of vegetable and fruit intake (e.g. from mixed dishes such as casseroles) were not explicitly included in the scoring of the questionnaire. This complicates the estimation of the intake of certain food groups (e.g. cruciferous vegetables and citrus fruits). The point estimates of the intake of these groups should be interpreted with some caution. One should also be cautious in interpreting the FFQ estimates because of the well-known problems associated with dietary assessment using the methodology ${ }^{13}$.

The estimated absolute food intake (servings per week) and nutrient intake are higher in the present study than reported in other projects ${ }^{4,7,8}$. This might reflect differences in the methods used to obtain the dietary information. However, even with the higher mean intakes than reported in the literature, a large proportion of smokers fail to eat enough fruit and fruit juice to meet the standards expected to reduce cancer risk. This is particularly true for heavy smokers.

Regular smoking is a strong risk factor for cancer. If smokers also eat a diet low in fruit and vegetables, they are at even higher risk of cancer. A comprehensive cancer prevention intervention for smokers should adopt a multifactorial approach and include dietary counselling with respect to increasing fruit and vegetable intake.

\section{Acknowledgements}

The OHS was funded by the Ontario Ministry of Health. The analyses reported in this article were initiated and conducted by the author and received no external funding. The opinions expressed in this article are those of the author and do not necessarily imply endorsement by his employer or the Ontario government.

\section{References}

1 Baron JA, Rohan TE. Tobacco. In: Schottenfield D, Fraumeni JF Jr, eds. Cancer Epidemiology and Prevention. New York: Oxford University Press; 1996: 269-89.

2 Block G, Patterson B, Subar A. Fruit, vegetable, and cancer prevention: a review of the epidemiological evidence. Nutr. Cancer 1992; 18: 1-29.

3 Zondervan KT, Ocke MC, Smit HA, Seidell JC. Do dietary and supplementary intakes of antioxidants differ with smoking status? Int. J. Epidemiol. 1996; 25: 70-9.

4 Subar AF, Harlan LC. Nutrient and food group intake by tobacco use status: the 1987 National Health Interview Survey. Ann. NY Acad. Sci. 1993; 686: 310-21.

5 Subar AF, Harlan LC, Mattson ME. Food and nutrient intake differences between smokers and non-smokers in the US. Am. J. Public Health 1990; 80: 1323-9.

6 Whichelow MJ, Erzinclioglu SW, Cox BD. A comparison of the diets of non-smokers and smokers. Br.J. Addiction 1991; 86: $71-81$.

7 Margetts BM, Jackson AA. Interactions between people's diet and their smoking habits: the Dietary and Nutritional Survey of British Adults. Br. Med. J. 1993; 307: 1381-4.

8 Morabia A, Wynder EL. Dietary habits of smokers, people who never smoked, and ex-smokers. Am.J. Clin. Nutr. 1990; 52: $933-7$.

9 Fehily AM, Phillips KM, Yarnell JWG. Diet, smoking, social class, and body mass index in the Caerphilly Heart Disease Study. Am. J. Clin. Nutr. 1984; 40: 827-33.

10 Ontario Health Survey 1990. Users Guide, Volume 1, Documentation. Toronto, Ontario Ministry of Health, 1993.

11 Ostbye T, Pomerleau J, Speechley M, Pederson LL, Speechley KN. Correlates of body mass index in the 1990 Ontario Health Survey. Can. Med. Assoc. J. 1995; 152: 1811-17.

12 Block G, Hartman AM, Dresser CM, Carroll MD, Gannon J, Gardner L. A data-based approach to diet questionnaire design and testing. Am. J. Epidemiol. 1986; 124: 453-69.

13 Bright-See E, Catlin G, Godin G. Assessment of the relative validity of the Ontario Health Survey food frequency questionnaire. J. Can. Diet. Assoc. 1994; 55: 33-8.

14 Bright-See E. Personal communication, 1993.

15 Vitamin A and lung cancer. In Willett W, ed. Nutritional Epidemiology. New York: Oxford University Press; 1990: 292-310. 


\section{Appendix 1}

List of foods in food group (including question number as on the original OHS questionnaire).

(1) All vegetables: French Fried, Home Fried or Pan Fried Potatoes (FQ155), Any Other Potatoes (baked, mashed, salad) (FQ156), Broccoli (FQ157), Carrots (FQ158), Corn (FQ159), Green Peas (FQ160), Beans (green, string or yellow) (FQ161), Any Other Beans, Peas or Lentils (FQ162), Squash, all types (FQ163), Salad, combination lettuce/tomato (FQ164), Any Other Salad (Coleslaw, Carrot, Bean, Spinach) (FQ165), Any Other Vegetables such as cabbage and Brussel sprouts (FQ166), Potato Chips (FQ188).

(2) Cruciferous vegetables: Broccoli (FQ157), Any Other Vegetables such as cabbage and Brussel sprouts (FQ166).

(3) Potatoes (all): Fried, Home Fried or Pan Fried Potatoes (FQ155), Any Other Potatoes (baked, mashed, salad) (FQ156), Potato Chips (FQ188).
(4) Potatoes (excluding potato chips): Home Fried or Pan Fried Potatoes (FQ155), Any Other Potatoes (baked, mashed, salad) (FQ156).

(5) Fruit (all): Apples, Applesauce (FQ168), Bananas (FQ169), Oranges, Nectarines (FQ170), Pears, Peaches (FQ171), Raisins, Prunes, Dried Fruit (FQ172), Any Other Fruit (e.g. berries, fruit cocktail) (FQ173).

(6) Fruit (non-citrus): Apples, Applesauce (FQ168), Bananas (FQ169), Pears, Peaches (FQ171), Raisins, Prunes, Dried Fruit (FQ172), Any Other Fruit (e.g. berries, fruit cocktail) (FQ173).

(7) Fruit (citrus): Oranges, Nectarines (FQ170), Orange Juice (FQ174), Apple, Other Citrus Juice (FQ175).

(8) Juice (fruit and vegetable): Juice (FQ174), Apple, Other Citrus Juice (FQ175), Tomato, Mixed Vegetable Juice (FQ176). 